\title{
Sludge bio-drying: Effective to reduce both antibiotic resistance genes and mobile genetic elements
}

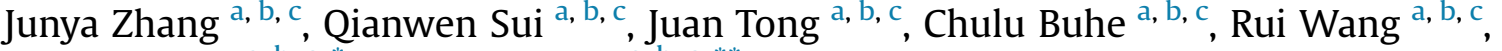 \\ Meixue Chen ${ }^{\mathrm{a}, \mathrm{b}, \mathrm{c}, *}$, Yuansong Wei ${ }^{\mathrm{a}, \mathrm{b}, \mathrm{c}, * *}$ \\ a State Key Joint Laboratory of Environmental Simulation and Pollution Control, Research Center for Eco-Environmental Sciences, Chinese Academy of \\ Sciences, Beijing, 100085, China \\ ${ }^{\mathrm{b}}$ Department of Water Pollution Control Technology, Research Center for Eco-Environmental Sciences, Chinese Academy of Sciences, Beijing 100085, China \\ ${ }^{c}$ University of Chinese Academy of Sciences, Beijing 100049, China
}

\section{A R T I C L E I N F O}

\section{Article history:}

Received 6 June 2016

Received in revised form

25 September 2016

Accepted 26 September 2016

Available online 28 September 2016

\section{Keywords:}

Sludge bio-drying

Antibiotic resistance genes

Aeration strategy

Mobile genetic elements

\begin{abstract}
A B S T R A C T
Sewage sludge is considered as one of major contributors to the increased environmental burden of ARGs. Sludge bio-drying was increasingly adopted due to its faster sludge reduction compared with composting. The fate of ARGs during full-scale sludge bio-drying was investigated to determine whether it could effectively reduce ARGs, and the contributions of bacterial community, horizontal gene transfer (HGT) through mobile genetic elements (MGEs) and co-selection from heavy metals to ARGs profiles were discussed in detail. Two piles with different aeration strategies (Pile I, the improved and Pile II, the control) were operated to elucidate effects of aeration strategy on ARGs profiles. Results showed that sludge bio-drying could effectively reduce both most of targeted ARGs (0.4-3.1 logs) and MGEs (0.8-3.3 logs) by the improved aeration strategy, which also enhanced both the sludge bio-drying performance and ARGs reduction. The enrichment of ARGs including ermF, tetX and sulli could be well explained by the evolution of bioavailable heavy metals, not HGT through MGEs, and their potential host bacteria mainly existed in Bacteroidetes. Although changes of bacterial community contributed the most to ARGs profiles, HGT through MGEs should be paid more attention especially in the thermophilic stage of sludge bio-drying.
\end{abstract}

() 2016 Elsevier Ltd. All rights reserved.

\section{Introduction}

Antibiotic resistance has become of a global concern, and a range of policy initiatives have been launched to combat it (Dar et al., 2016). As indicated by the World Health Organization (WHO) in May 2014 (Versporten et al., 2014), antibiotic resistance is one of the most serious public health issues of our time. The occurrence of antibiotic resistance genes (ARGs) in municipal wastewater treatment plants (WWTPs) has become a research hotspot, and numerous studies have detected ARGs at all stages of the municipal wastewater treatment processes, including influent,

\footnotetext{
* Corresponding author. Research Center for Eco-Environmental Sciences, Chinese Academy of Sciences, Beijing, 100085, China.

** Corresponding author. Research Center for Eco-Environmental Sciences, Chinese Academy of Sciences, Beijing, 100085, China.

E-mail addresses: zjyzjjzmt@gmail.com (J. Zhang), mxchen@rcees.ac.cn (M. Chen), yswei@rcees.ac.cn (Y. Wei).
}

primary settling tank, aeration tank, secondary effluent, and excess sludge. The vast majority of these ARGs are discharged from excess sludge, contributing ca. 1000 times to the release of the ARGs in the environment than effluent (Munir et al., 2011). Thus, sewage sludge treatment should be targeted as a key point to reduce the quantity of ARGs discharged from WWTPs (Burch et al., 2013a).

Sludge bio-drying, derived but different from sludge composting, was considered as an innovative treatment of sludge with high moisture content (MC) through the aerobic degradation of organic substances along with aeration and turning to evaporate water (Zhao et al., 2010). The primary purpose of sludge bio-drying was for the sludge reduction through MC reduction, different from that of composting was resource utilization and full stabilization (Zhao et al., 2010, 2011). Such difference leads to the completely different process goals and operation parameters between sludge bio-drying and composting. For instance, MC should be kept $50-60 \%$ to realize the full stabilization of organic matter during sludge composting (Zhao et al., 2010), while the MC should be removed as much as 
possible in the shortest time for sludge bio-drying. Furthermore, there was no maturation phase for sludge bio-drying, it was no more than enhanced physical aeration after cooling phase to maximize the MC reduction (Zhang et al., 2015), resulting in much higher energy consumption for sludge bio-drying. The product of sludge bio-drying could not only be used as bio-fuel for the incineration but also as the cover soil in the landfill site and the landscaping (Zhang et al., 2015; Yang et al., 2014), or the soil amendment similar to the product of air-drying (Class B treated solids) as suggested previously (Burch et al., 2014; Yang et al., 2014). However, the typical period of composting (30-50 days) was much longer than that (10-25 days) of sludge bio-drying (Zhang et al., 2015), and thus, there should be a balance between energy and time consumption along with land area required to determine which process should be chosen.

Along with increasing amounts of municipal wastewater treatment (Wei et al., 2003), the amount of sewage sludge production in China has reached to 6.25 million tons dry solids in 2013 at an average annual growth of 13\% from 2007 to 2013 (Jin et al., 2014), and application of sludge bio-drying has become more and more attractive, e.g., the biggest sludge bio-drying plant treating 1000 tonnes $\mathrm{d}^{-1}$ of dewatered sludge (ca. $80 \%$ of MC, wet weight) has been built and operated in Shenyang since 2010. However, there was little available information on the fate of ARGs during sludge bio-drying. Because of the amounts of ARGs in sludge, there is a need to assess the potential of sludge bio-drying for ARGs reduction as what has been done for other sludge treatment technologies like aerobic digestion (Burch et al., 2013b), air-drying beds (Burch et al., 2013a), sludge composting (Zhang et al., 2016a) and anaerobic digestion (Zhang et al., 2016b), and efforts have been undertaken to optimize these sludge treatment technologies for reducing ARG quantities (Ma et al., 2011). Sludge bio-drying may provide a cost-effective way for removing ARGs from sewage sludge if they are found to reduce ARG concentrations effectively. Thus, it is of great concern to investigate the fate of ARGs and the effects of key operational parameters on ARGs profile during sludge biodrying.

Concerning the spread of ARGs in various environments, the effects of co-selection from heavy metals (Baker-Austin et al., 2006), horizontal gene transfer (HGT) (Zhang et al., 2016a), and changes of bacterial community (Udikovic-Kolic et al., 2014) have drawn more and more attention. While high levels of heavy metals existed in sewage sludge, and thus effects of heavy metals on ARGs profiles during sludge treatment should be emphasized. Furthermore, changes of bacterial community were demonstrated as the main driver of the evolution of ARGs in various environments (Zhang et al., 2016a, 2016b). For instance, Su et al. (2015) investigated the dynamics of ARGs and bacterial community using highthroughput PCR and sequencing during a lab-scale in-vessel sludge composting, results of mantel test and procrustes analysis indicated the significant correlation between ARGs contents and bacterial composition while partial RDA further confirmed the dominant contribution of bacterial communities to the dynamics of ARGs evolution compared to environmental factors and MGEs, and HGT via mobile genetic elements (MGEs) may also be facilitated with high density and diversity of microbial flora in sludge. Although sludge bio-drying was quite different from composting, bacterial community also changed significantly during sludge biodrying (Zhang et al., 2015). Therefore it would be of great help to clarify the contribution of various factors, not only environmental factors, bacterial community and MGEs, but also co-selection from heavy metals and operational parameters like aeration strategy, to the fate of ARGs during sludge bio-drying.

Thus the purposes of this study were to 1 ) investigate the fate of ARGs during sludge bio-drying to determine whether it could be used for both sludge reduction and ARGs control; 2) figure out effects of aeration strategy, the most important parameter of sludge bio-drying (Zhang et al., 2015), on ARGs profiles; 3) verify the different contributions to ARGs profiles during sludge bio-drying concerning co-selection from heavy metals, HGT via MGEs, and evolution of bacterial community.

\section{Materials and methods}

\subsection{Sludge bio-drying process}

The process description and aeration strategy design were described in detail elsewhere (Zhang et al., 2015). Briefly, the sludge bio-drying plant located in Shenyang, Liaoning province in China, was designed to treat 1000 tons of dewatered sludge at $80 \%$ of moisture content (MC) per day, employing horizontal agitated solid bed process (HASB) with forced aeration and mechanic turning. It was designed to reduce sludge MC from $80 \%$ to less than $40 \%$. There are 96 tunnels in total and each is $90 \mathrm{~m}$ length, $3 \mathrm{~m}$ width and $2.5 \mathrm{~m}$ height. According to aeration condition, each tunnel is divided into seven parts including one pre-mixed area and six different aeration areas (Area A, B, C, D, E and F), and their details are shown in Fig. S1. Two aeration strategies were adopted for two different tunnels (Table S1). The operational period of sludge bio-drying was set at 21 days, in which each tunnel was turned once a day along with the pile marching forward $4 \mathrm{~m}$ per day, and thus, the size of each pile as influent in this study was $4 \mathrm{~m}$ length, $3 \mathrm{~m}$ width and $2 \mathrm{~m}$ height. Pile I was designated as the improved designed according to the aeration need in different sludge bio-drying phases, while Pile II as the control. The design of the improved aeration strategy was described in detail in supporting information. Briefly, aeration was designed mainly to supply oxygen for microbial activity on area $A$ and $\mathrm{B}$; cool pile and keep sludge bio-drying progressed effectively on area C, D and E; evaporate MC on area F, respectively.

The dewatered sludge through centrifugation at average total solids content of ca. $20 \%$ and organic fraction of ca. $62 \%$ was mainly from WWTPs and a small proportion from industrial WWTPs in Shenyang. Prior to the bio-drying process, the dewatered sludge was mixed with the bio-dried sludge products to control the initial moisture content (MC) at approximately $60 \%$ on the basis of design requirement. The pre-dried sludge was collected through biodrying of dewatered sludge and rice husk previously. The aeration for oxygen supply, cooling and MC evaporation in sludge bio-drying was controlled by the time-temperature feedback mode.

\subsection{Sample collection and DNA extraction}

Pile I and Pile II were followed precisely throughout the sludge bio-drying process, in which samples were collected on days $1,3,5$, $7,11,14,17$ and 21, respectively. Because each pile was turned once per day, each pile could be considered to have been homogeneous. To obtain a representative solid sample, the surface area of each pile $(4 \times 3 \mathrm{~m})$ was diagonally divided into four parts, and five sampling points were chosen on the diagonals. Samples (100-200 g each) were collected at a pile depth of $10-15 \mathrm{~cm}$. The samples were mixed together, and a representative sample ( $100 \mathrm{~g})$ was acquired from the well mixed samples. Samples were stored in $-20{ }^{\circ} \mathrm{C}$ for further analysis.

$0.5 \mathrm{~g}$ of each sample was collected for DNA extraction in triplicate with the FAST DNA Spin Kit for Soil (MP Biomedicals, USA) according to the manufacture's protocol. The triplicate DNA extracts were then merged together for the following analysis. Extracted genomic DNA was detected and quantified using $1 \%$ agarose gel electrophoresis and NanoDrop 2000 (Thermo Scientific, USA), respectively, and then stored at $-20{ }^{\circ} \mathrm{C}$ until use. 


\subsection{Quantitative PCR ( $q P C R$ )}

The fate of ten frequently detected ARGs in sewage sludge throughout the sludge bio-drying process was tracked, as well as three selected mobile genetic elements (MGEs) including the class 1 integrase gene (intI1), the conjugative transposon Tn916-Tn1545 family (Tn916/1545) and one insertion sequence common region I gene (ISCR 1 ) representing the potential of the horizontal gene transfer (HGT). As for ten ARGs, six tetracycline resistance genes (tet $\mathrm{A}$, tet $\mathrm{G}$, tet $\mathrm{M}$, tet $\mathrm{X}$, tet $\mathrm{Q}$ and tet $\mathrm{W}$ ), two erythromycin resistance gene (ermB and ermF) and two sulfonamide resistance gene (sull and sulII) were selected according to types of antibiotics and main resistance mechanisms (antibiotic deactivation or degradation, efflux pump and target protection). Copper was reported as the second highest average concentration of eight concerned heavy metals at the order of $\mathrm{Zn}>\mathrm{Cu}>\mathrm{Cr}>\mathrm{Pb}>\mathrm{Ni}>\mathrm{As}>\mathrm{Cd}>\mathrm{Hg}$ in sewage sludge of China from 2006 to 2013 (Guo et al., 2014), and copper has been widely demonstrated to co-select for antibiotic resistance (Ji et al., 2012; Stepanauskas et al., 2005) and the evolution of copper resistance genes has been investigated in various environments (Amachawadi et al., 2013, 2015; Besaury et al., 2013; Xiong et al., 2015). Thus three selected copper resistance genes ( $t c r \mathrm{~B}, \operatorname{copA}$ and $p c o \mathrm{R}$ ) were quantified to represent the evolution of heavy metal resistance genes (MRGs) along with sludge bio-drying.

The detail information of qPCR was described elsewhere (Zhang et al., 2016a). Briefly, the target genes in each sample were quantified in triplicate with a standard curve and negative control. Standards for quantitative PCR were prepared through TA clone by Zhejiang Tianke Biotechnology Company (Zhejiang, China) and extracted using an Axygen mimi-prepare Plasmid kit (Axygen, USA). The concentrations of the standard plasmids were determined with the Nanodrop ND-2000 (Nanodrop, USA). The standard curve for each qPCR assay consisted of a 10-fold dilution series of the qPCR standard containing at least 5 points. Amplification efficiencies were between $88 \%$ and $99 \%$. The specificity was assured by the melting curves and gel electrophoresis. The primers, annealing temperature used in qPCR and the corresponding detail amplification efficiencies were summarized in Tables S2 and S3.

\subsection{Heavy metal analysis}

Total heavy metal concentrations were often used to assess the co-selection from heavy metals. However, the selection pressure caused by heavy metals depend on the form and speciation that is bioavailable (Devi and Saroha, 2014; Li et al., 2010; Roosa et al., 2014). Thus, total heavy metals and copper speciation corresponding to the copper resistance genes were both determined in this study.

After freeze-dried and grounded to sieve through $100 \mu \mathrm{M}$ mesh, $0.1 \mathrm{~g}$ of each sludge bio-drying sample was digested in a $8-\mathrm{mL}$ mixture of aqua regia and hydrofluoric acid $(3: 1, v / v)$ according to the microwave assisted digestion method 3051A (USEPA, 2007), using a microwave digestion instrument (Mars 5, CEM, USA). Then perchloric acid $(1 \mathrm{~mL})$ alone was added and the sample was evaporated at $150{ }^{\circ} \mathrm{C}$ until the appearance of white fumes. The residue was dissolved in deionized water for determining total heavy metals. Copper speciation analysis was determined using Tessier method (Tessier et al., 1979), in which total copper were divided into five fractions as exchangeable, weakly complexed and bound to carbonate, bound to Fe-Mn oxides, bound to organic matter and sulphide, and residual. The recovery rate of copper speciation analysis was in the range of $87-130 \%$, which was consistent with previous study (Wang et al., 2014a,b). According to previous studies (Diop et al., 2015; Zhang et al., 2016a), the first three speciations were regarded as bioavailable. The heavy metal concentrations including $\mathrm{Cu}, \mathrm{Zn}, \mathrm{As}, \mathrm{Cr}, \mathrm{Pb}, \mathrm{Cd}, \mathrm{Mn}$ and $\mathrm{Ni}$ were determined using inductively coupled plasma-mass spectrometry (ICP-MS) or optical emission spectrometry (ICP-OES) according to the concentrations of different heavy metals. Two parallel samples were treated, and then each sample was tested in triplicate.

\subsection{Data analysis}

The visualization of ARGs evolution was realized using Origin 9.0 (IBM, USA). The gene copies indicated the absolute copy numbers present per unit of dry weight (DW), while the normalized copy number by $16 \mathrm{~S}$ rRNA was regarded as the abundance. Procrustes analyses, redundancy analysis (RDA) and partial RDA were performed using Canoco 5.0 (Microcomputer Power, USA). The Spearman correlation was performed using SPSS 21.0 (IBM, USA), and a $p$ value $<0.05$ was considered statistically significant. Spearman's correlation coefficients for pairwise ARGs, copper resistance genes and heavy metals were visualized in the form of heatmap using pheatmap packages in R. The quantities of ARGs reduced during sludge bio-drying were fit to a first-order kinetic model (ExpDec1) using Origin 9.0 (Microsoft, USA). The first-order kinetic model was initially hypothesized based on the previous studies in which it fits the evolution of ARGs well in several different environmental conditions (Burch et al., 2013a; Engemann et al., 2008). Evolution of bacterial community during sludge biodrying has been analyzed previously using high-throughput sequencing method targeting the 16S rRNA V4 region (Zhang et al., 2015). To clarify the correlation between the evolution of ARGs and the changes of bacterial community, mantel tests were conducted using PAleontological STatistics software (PAST 3.07). Network analysis based on the Spearman analysis between ARGs and the bacterial community composition (based on OTU) was determined using the Gephi platform (Bastian et al., 2009).

\section{Results and discussion}

\subsection{Fate and kinetics of ARGs during sludge bio-drying}

As shown in Figs. 1 and 2, sludge bio-drying could reduce most of ARGs (except ermF, sulII and tetX) concerning either gene copies or abundance, although there are some differences between the two piles. Total bacterial biomass reflected by $16 \mathrm{~S}$ rRNA gene copies fluctuated with time, and reached the maximum at the maximum pile temperature for both piles (Figs. S3 and S4). This may be due to the highest bacterial proliferation and activity at the thermophilic stage. Sludge bio-drying could reduce the microbial biomass at the end in both piles. Also, there was significantly positive correlation $(p<0.05)$ between ARGs that were reduced and bacterial biomass, which indicated the importance of evolution of biomass on ARGs profiles.

The ARGs prevalence changed significantly during sludge biodrying, and sull was predominant at the beginning while ermF, sulII and tetX were dominant at the end in both piles. The tetM and tet $\mathrm{W}$ were reduced the most in both piles (3.09 logs, 0.81 logs and 2.76 logs, 1.04 logs for Pile I and Pile II, respectively), while tetX was enriched the most in both piles (1.23 logs and 1.96 logs for Pile I and Pile II, respectively). The most enrichment of tetX during sludge bio-drying was also observed in sludge composting (Zhang et al., 2016a). As indicated before, the enrichment of tetX may be not a bad thing, because it could degrade tetracyclines and thus reduce the further selective pressure from tetracyclines (Zhang et al., 2016a). Concerning the absolute genes copies, in contrast to the reduction by $0.4-3.1$ logs for erm $\mathrm{B}$, sulI, tetA, tet $\mathrm{G}$, tet $\mathrm{M}$, tet $\mathrm{Q}$ and tetW in Pile I, ermF, sulII and tetX increased by $0.45-1.96$ logs in both piles. The changes of the abundance of ARGs exhibited similar 
Pile I

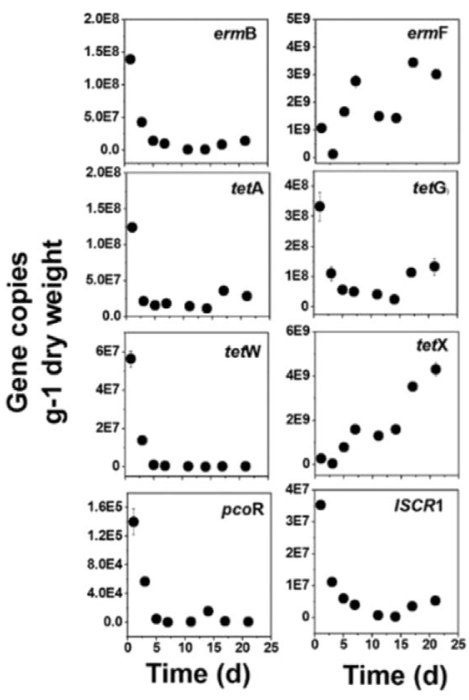

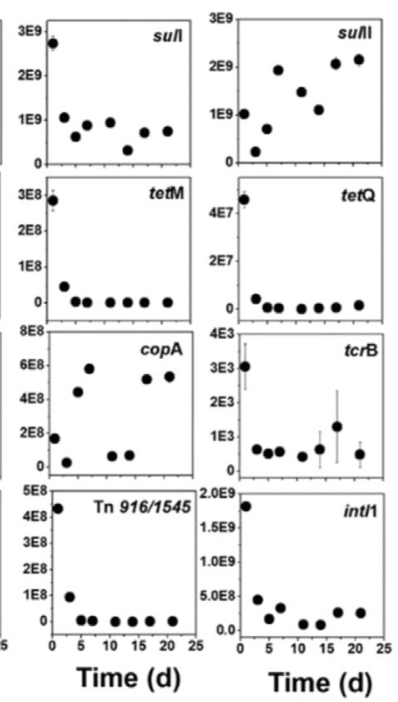

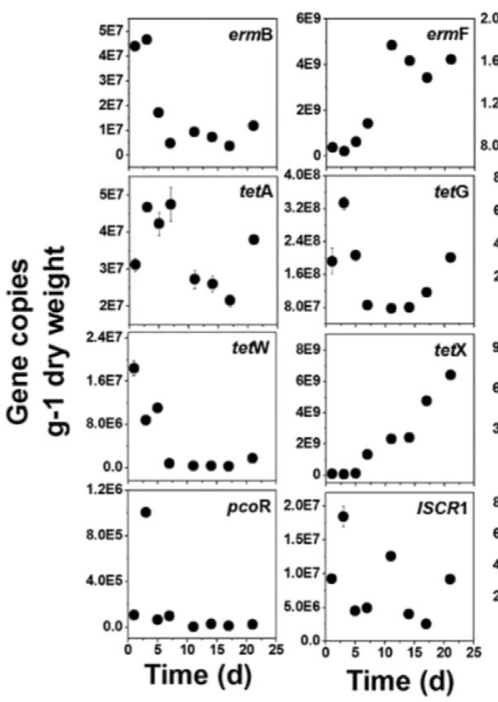

Pile II

Fig. 1. Changes of the absolute gene copies of ARGs, MGEs and MRGs in Pile I and Pile II during sludge bio-drying.

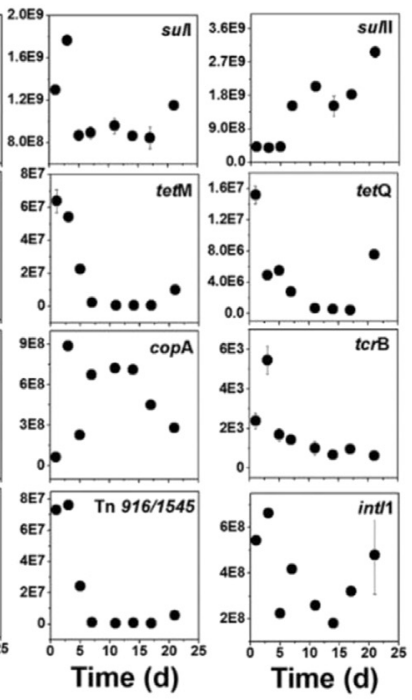

Pile I

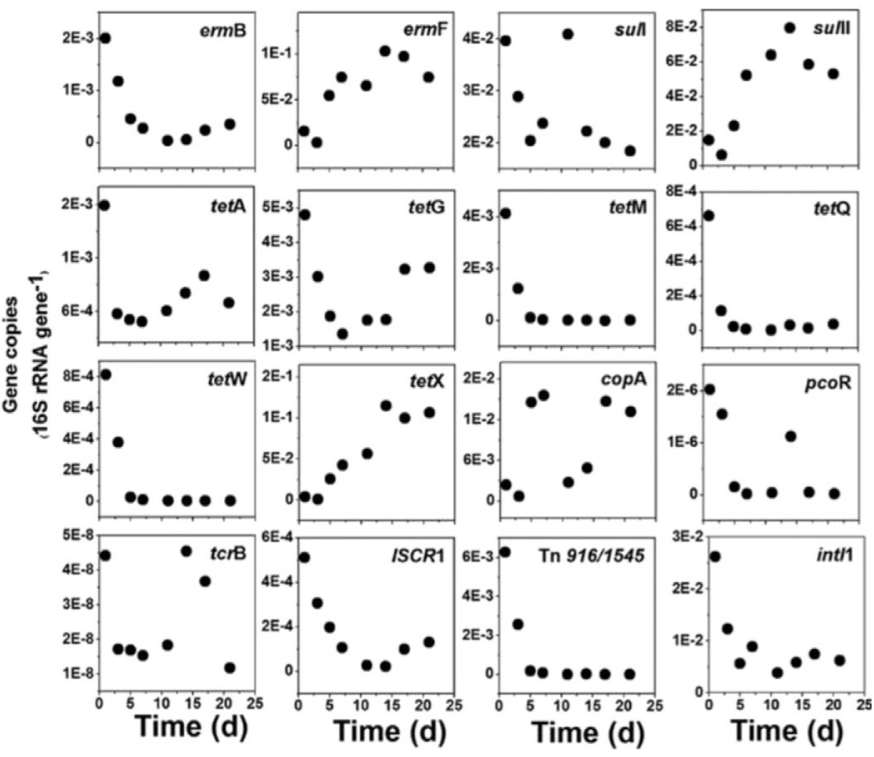

Pile II

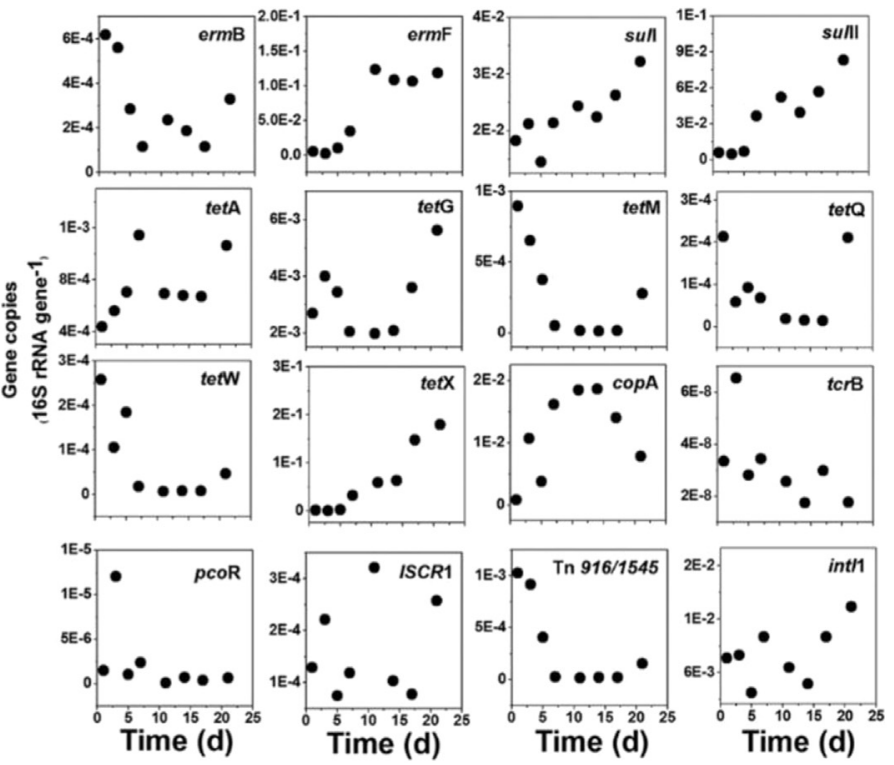

Fig. 2. Evolution of the abundance of ARGs, MGEs and MRGs in Pile I and Pile II during sludge bio-drying.

patterns to that of genes copies (Fig. 2).

First-order kinetic models described trends of absolute gene copies reduction during sludge bio-drying in both piles very well (Table 1), and the models could also provide a useful interpretive tool and basis of comparison to other studies that may consider different gene targets and environmental conditions (Burch et al., 2013a). Most (24 of 26) first-order kinetic coefficients for target genes in both piles were statistically significant $(p<0.05)$, and Pile I had some advantages over Pile II concerning the ARGs reduction through the models analysis. For instance, half-lives for ARGs and MGEs varied from $0.4 \mathrm{~d}$ (tetA) to $1.5 \mathrm{~d}$ (ermB) for Pile I, while $1.5 \mathrm{~d}$ (tetQ) to $26.1 \mathrm{~d}$ (tetA) for Pile II, respectively, and their corresponding half-lives $\left(t_{1 / 2}\right)$ in Pile II were $2.6($ ermB $) \sim 65.3($ tet $A)$ times higher than that in Pile I. The great distinction between Pile I and Pile II emphasized the importance of the optimization of operational parameters considering the ARGs control. Besides, sludge bio-drying showed its advantages of reducing some ARGs over anaerobic digestion, air-drying and aerobic digestion, i.e., halflives of tetA, ermB, tetW, sull and 16S rRNA in Pile I were much shorter than those (Table 1). However, tetX increased during sludge bio-drying, while its reduction was observed in anaerobic digestion, air-drying and aerobic digestion.

\subsection{Effects of aeration strategy on the fate of ARGs}

The removal efficiency was $663.5 \mathrm{~min} /(1 \% \mathrm{MC}$ removal $)$ and $673.1 \mathrm{~min} /(1 \% \mathrm{MC}$ removal) for Pile I and Pile II, respectively, and the MC removal efficiency in Pile I was higher than that in Pile II 
Table 1

First-order co-efficients for ARGs, MGEs and copper resistance genes reduced during sludge bio-drying, and the corresponding $t_{1 / 2}$ observed in previous studies.

\begin{tabular}{|c|c|c|c|c|c|c|c|c|c|c|}
\hline \multirow[t]{2}{*}{ Target ARG } & \multicolumn{2}{|l|}{$p$} & \multicolumn{2}{|l|}{$\mathrm{r}^{2}$} & \multicolumn{6}{|c|}{$\mathrm{t}_{1 / 2}(\mathrm{~d})$} \\
\hline & Pile I & Pile II & Pile I & Pile II & Pile I & Pile II & $\begin{array}{l}\text { Anaerobic digestion } \\
\text { (Diehl and Lpara, 2010) }\end{array}$ & $\begin{array}{l}\text { Aerobic digestion } \\
\text { (Burch et al., 2013b) }\end{array}$ & $\begin{array}{l}\text { Air-drying } \\
\text { (Burch et al., 2013a) }\end{array}$ & $\begin{array}{l}\text { Land application } \\
\text { (Burch et al., 2013a) }\end{array}$ \\
\hline ermB & $<1 \times 10^{-4}$ & $5 \times 10^{-3}$ & 0.99 & 0.73 & 1.5 & 3.9 & & 3.6 & 6.4 & 13 \\
\hline tetA & $2 \times 10^{-4}$ & 0.34 & 0.94 & 0.36 & 0.4 & 26.1 & 2.9 & 4.4 & 8.8 & 25 \\
\hline tetG & $2 \times 10^{-4}$ & 0.02 & 0.80 & 0.05 & 1.0 & 5.0 & & & & \\
\hline tet $\mathrm{M}$ & $<1 \times 10^{-4}$ & $2 \times 10^{-4}$ & 0.99 & 0.86 & 1.1 & 3.6 & & & & \\
\hline tetQ & $<1 \times 10^{-4}$ & 0.01 & 0.99 & 0.66 & 0.8 & 1.5 & & & & \\
\hline tetw & $<1 \times 10^{-4}$ & $3 \times 10^{-3}$ & 0.99 & 0.83 & 1.4 & 3.7 & 3.8 & 2.8 & 7.3 & 16 \\
\hline sulI & $2 \times 10^{-4}$ & $1 \times 10^{-3}$ & 0.90 & 0.14 & 1.1 & 4.1 & & 4.6 & 35.3 & 53 \\
\hline ISCR 1 & $<1 \times 10^{-4}$ & 0.05 & 0.97 & 0.16 & 1.6 & 6.2 & & & & \\
\hline Tn916/1545 & $<1 \times 10^{-4}$ & $7 \times 10^{-3}$ & 0.99 & 0.79 & 1.3 & 4.1 & & & & \\
\hline intI 1 & $<1 \times 10^{-4}$ & $6 \times 10^{-4}$ & 0.97 & 0.13 & 1.1 & 3.4 & 1.0 & 6.3 & 31.7 & 30 \\
\hline $16 s$ rRNA & $1 \times 10^{-4}$ & $1 \times 10^{-4}$ & 0.62 & 0.75 & 1.2 & 7.42 & & 5.5 & 36.7 & 93 \\
\hline pcoR & $<1 \times 10^{-4}$ & 0.39 & 0.96 & 0.05 & 1.8 & 11.1 & & & & \\
\hline tcrB & $1 \times 10^{-4}$ & 0.04 & 0.87 & 0.31 & 0.2 & 9.7 & & & & \\
\hline
\end{tabular}

through the improvement of aeration strategy, while the higher aeration time and lower MC removal in Area F for Pile I compared to Pile II (aeration time, $7200 \mathrm{~min}$ vs $3600 \mathrm{~min}$ ) described in our previous study (Zhang et al., 2015) indicated that the aeration strategy of Pile I in area F needed further improvement. The aeration strategy was the most important operation parameter for sludge bio-drying (Winkler et al., 2013; Navaee-Ardeh et al., 2010), and it had significant influences on the fate of ARGs in this study. The aeration rate increasing significantly along with sludge biodrying appeared to select for bacterial cells containing tetX which is specific to aerobes (Burch et al., 2014). While tetQ and tetW (ribosomal protection protein mechanism, RPP) are more frequently found in anaerobes (Roberts, 2005), and previous study observed that alternate anoxic/oxic treatment could select against microbes carrying the RPP genes (Cheng et al., 2013). Therefore, the high reductions of tet $\mathrm{Q}$ tet $\mathrm{W}$ and tet $\mathrm{M}$ and the significantly increase of tetX could be caused by the aeration strategy used during sludge bio-drying.

Concerning the evolution of ARGs, all the ARGs decreased after thermophilic phase, while some ARGs especially ermF, sulII and tetX rebounded significantly, and there was a great difference of the rebound between Pile I and Pile II (Figs. 1 and 2). Generally, ARGs in Pile II showed higher degree of rebound than Pile I. For instance, erm $\mathrm{B}$, tet $\mathrm{M}$, tetW and sull remained constant for both piles. In contrast, tetA, tet $\mathrm{G}$ and tet $\mathrm{Q}$ rebound a lot, especially in Pile II. This resulted in significant difference $(p<0.05)$ of the final ARGs reduction rates between Pile I and Pile II (Table S4). This was consistent with previous study about anaerobic digestion that the thermophilic stage led to statistically significant reductions in the quantities of ARGs, but the mesophilic stage was generally ineffective and ARGs thus came to rebound (Ghosh et al., 2009). The final reduction efficiency of ARGs of Pile I was generally higher than that of Pile II (Table S4), which might suggest that experiencing higher biomass temperature due to the improved aeration strategy resulted in higher ARGs reduction and fewer ARGs rebound in the final. This needs further research. Besides, through the first-order kinetic models analysis, the aeration strategy has the biggest influence on the tetA reduction ( $t_{1 / 2}$, Pile I, $0.4 \mathrm{~d}$ vs Pile II, $\left.26.1 \mathrm{~d}\right)$, and these all highlighted the importance of aeration strategy for ARGs control during sludge bio-drying.

\subsection{Effects of heavy metals on ARGs evolution}

Considering co-selection of heavy metals and antibiotics, we should not simply focus on total heavy metals concentrations, but also heavy metal speciation and minimum co-selection concentrations (MCCs) of different heavy metals (Seiler and Berendonk, 2012; Zhang et al., 2016a). Part of total heavy metals might be not bioavailable, and different heavy metals have significantly different effects on microbes. For instance, As and Cd are toxic to microbes and cannot be used as nutrition, and they can present co-selection at very low concentration. While $\mathrm{Cu}$ and $\mathrm{Zn}$ are imperative elements for microbes and their MCCs may be much higher (Seiler and Berendonk, 2012). The evolution of total heavy metals and copper speciation was shown in Figs. S5 and S6. Copper was mainly bound to organic matter and sulphide (77.9-87.8\%), only with $5.1-13.7 \%$ of copper remaining in the bioavailable speciation and less than $10 \%$ left in the residual speciation. Along with sludge bio-drying, BioCu increased a lot for both piles, and there was no positive correlation between total $\mathrm{Cu}$ and $\operatorname{copA}$, while the correlation between BioCu and copA was significant in both piles (Fig. 3). This indicated the importance of heavy metal speciation analysis when considering the co-selection of heavy metals on ARGs, and bioavailable heavy metals might reflect the real selection of heavy metals on microbes. According to spearman correlation analysis (Fig. 3), BioCu has significantly positive correlations with tetX, sulII and ermF (Fig. 3, subgroup B), which might indicate the co-selection from heavy metals contributed to the enrichment of these ARGs. While As and Cd had much lower MCCs compared with $\mathrm{Cu}$, and they had significantly positive correlation with tet $\mathrm{M}$, tet $\mathrm{Q}$ and tet $\mathrm{W}$ which were reduced after sludge bio-drying (Fig. 3, subgroup A).

Considering that $p c o \mathrm{R}$ and $t c r \mathrm{~B}$ are a kind of regulator for copper resistance and transferable copper resistance genes, respectively, they could represent the potential of copper resistance along with copA, and there were significant correlation between MGEs and pcoR along with tcrB. They both were reduced significantly after sludge bio-drying. Transferable copper resistance (tcrB) in Enterococcus species has previously been found to be associated with erm B and tetM (Amachawadi et al., 2013). In this study, both tcrB and $p c o \mathrm{R}$ have significantly positive correlations $(p<0.05)$ with many ARGs (tetM, ermB, tetW, tetQ) in both piles (Fig. 3), which further suggested the existence of co-selection from heavy metals through co-occurrence.

\subsection{The role of MGEs on the fate of ARGs}

Class 1 integrons (intI1), which integrates and transfers ARGs via gene cassettes, is the most prevalent MGEs in various environments (Mazel, 2006). Inserting sequence common regions (ISCR) is a newly highlighted complex integron element which can integrate non-cassette resistance genes (Toleman et al., 2006). They both 

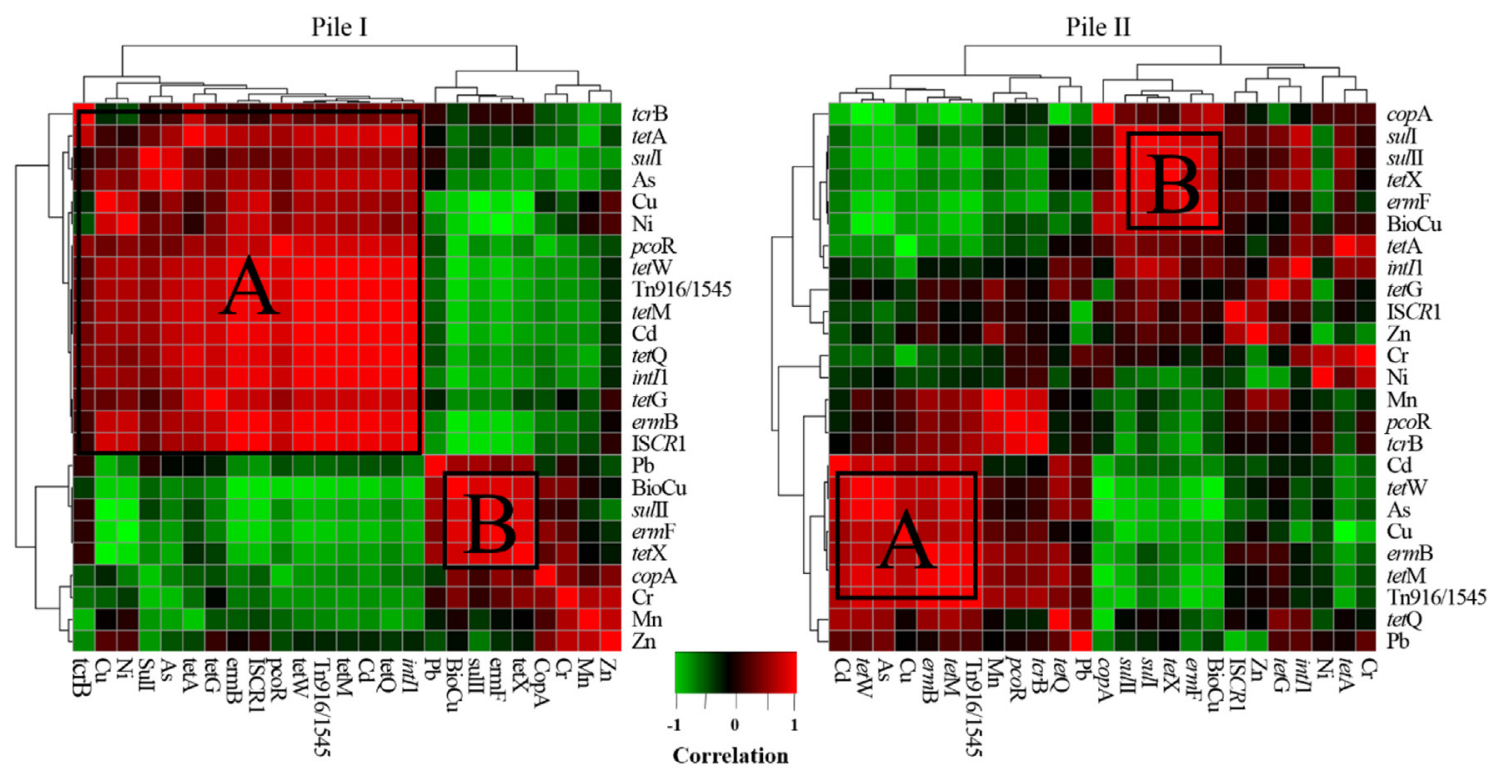

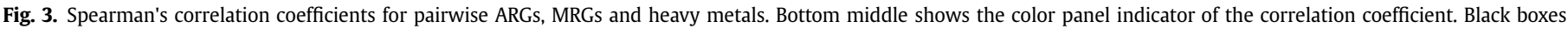

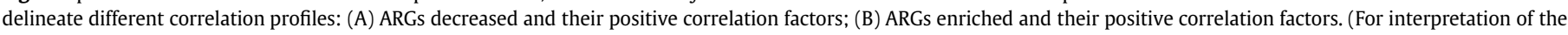
references to colour in this figure legend, the reader is referred to the web version of this article.)

contribute to the spread and proliferation of ARGs and multiresistance of host bacteria. Tn916/1545 is a kind of conjugative transposon which can transpose among chromosomes and plasmids, as well as transpose between different microbes including $\mathrm{G}^{+}$ and $\mathrm{G}^{-}$through conjugation (Clewell et al., 1995). Once ARGs entered into more microbes with the help of MGEs, ARGs would increase along with cell proliferation. Sludge bio-drying reduced both MGEs gene copies and abundance in both piles.

Acquisition of ARGs by HGT through MGEs has an alarming role on the development and spread of ARGs, and there were significantly positive correlation between different MGEs and ARGs. For instance, intI 1 had significant correlation with tet $\mathrm{M}$, tet $\mathrm{Q}$ tet $\mathrm{W}$, ermB, tetG, tetA and sulI in Pile I. These kinds of correlations were frequently elucidated in various environments, which indicated the importance of MGEs on the evolution of ARGs. Although ARGs reduction of all detected ARGs in Pile I was higher than Pile II, there were more ARGs presenting significantly positive correlations $(p<0.01)$ with MGEs for Pile I than Pile II (Fig. 3). Generally, those ARGs associated with MGEs entering into environment could do more harm (Wang et al., 2014a,b). This may suggest that we should not only try to reduce ARGs, but also know how to reduce ARGs considering the relationship between MGEs and ARGs, that is, reduce the spread of ARGs through HGT. While concerning the enrichment of ermF, sulII and tetX, there was somewhat negative correlation with MGEs, which indicated that HGT through MGEs might not facilitate their proliferation during sludge bio-drying.

\subsection{Effects of changes of bacterial community on ARGs profiles}

ARGs reduction in both piles were significantly positive correlated with 16S rRNA gene copies $(p<0.05)$, which demonstrated that biomass played an important role in ARGs reduction, similar to previous studies (Burch et al., 2013a). Besides, it was assumed that the composition of microbial community would affect the occurrence and abundance of ARGs, not just microbial biomass. Procrustes analysis was used to figure out the correlation between the evolution of ARGs and changes of bacterial community composition during sludge bio-drying as suggested previously (Zhang et al., 2016a). The results showed that the explanatory variables accounted for $82.3 \%$ and $73.0 \%$ in Pile I and Pile II, respectively, that is the degree of the evolution of ARGs could be explained by the changes of bacterial community. Also, the correlation between the first two axes was significantly positive in both piles (Fig. 4). Mantel tests based on Bray-Curtis distance further elucidated the significantly positive correlation $(p<0.01)$ between evolution of ARGs and changes of bacterial community in both piles.

Network analysis could be used to reflect ARGs potential host bacteria in various environments (Zhang et al., 2016a). As shown in Fig. 5, network analysis between evolution of ARGs and changes of bacterial community during sludge bio-drying could be divided into two parts of ARGs increased and ARGs decreased. Sludge biodrying could reduce most of ARGs and their potential host bacteria, while ermF, sulII and tetX along with their potential host bacteria like Sphingobacterium, Pedobacter, Parapedobacter were enriched. However, tetX was only found in Sphingobacterium and Bacteroides, and ermF in Bacteroides in previous study (McArthur et al., 2013). The significantly positive correlation with ARGs may be due to its functional connection with real antibiotic resistance bacteria, while these potential host bacteria may have the biggest chance of becoming the ARBs through HGT as suggested before (Zhang et al., 2016b). Network analysis further elucidated the significant correlation between evolution of ARGs and changes of bacterial community composition.

\subsection{The variation of the contributors to the evolution of ARGs}

According to RDA analysis (Fig. S7), 96.9\% of the variation of the evolution of ARGs in this study could be explained by MGEs, coselection from heavy metals and bacterial community $(p=0.002)$. Bacteroidetes and BioCu could explain the evolution of ermF, tetX and sulII, while Firmicutes accounted for the patterns at the beginning in both piles, and the effects of MGEs on the evolution of tetG and tetQ should not be overlooked. To rank the variation of the contribution to the evolution of ARGs as a whole, partial RDA was further conducted by designating the explanatory variables and covariates as suggested previously (Zhang et al., 2016b). It was concluded that the bacterial community contributed the most to the ARG changes during sludge bio-drying, followed by MGEs and 
Pile I

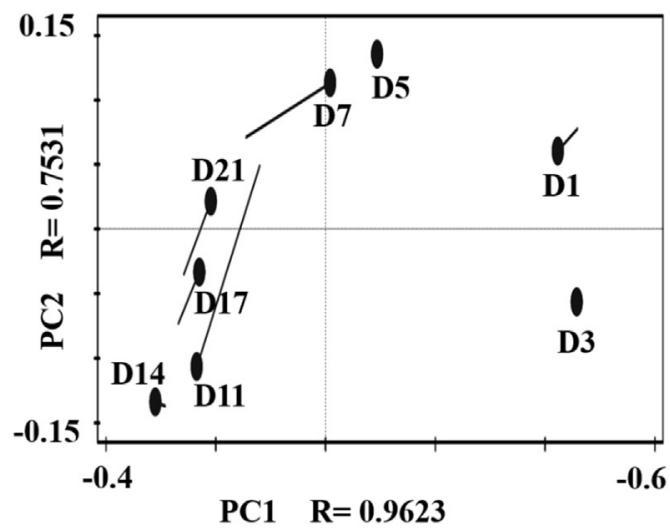

Pile II

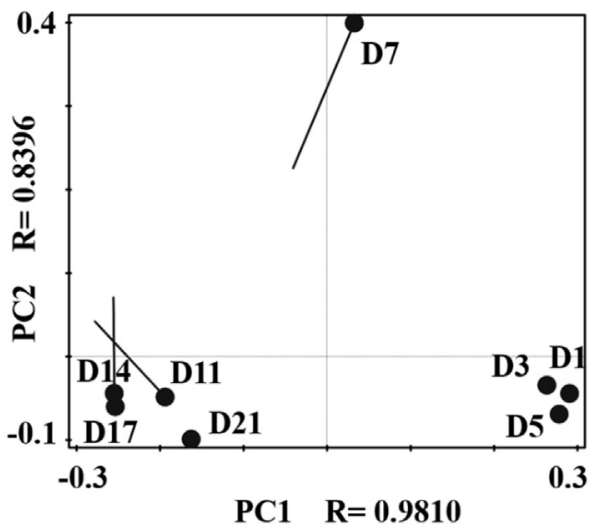

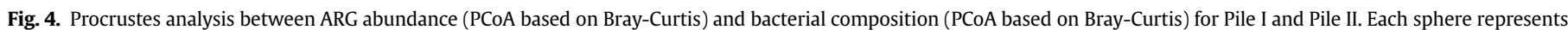
a sample variable. The pair-wise Pearson linear correlation between corresponding axes (PC1 and PC2) was shown as the R value.

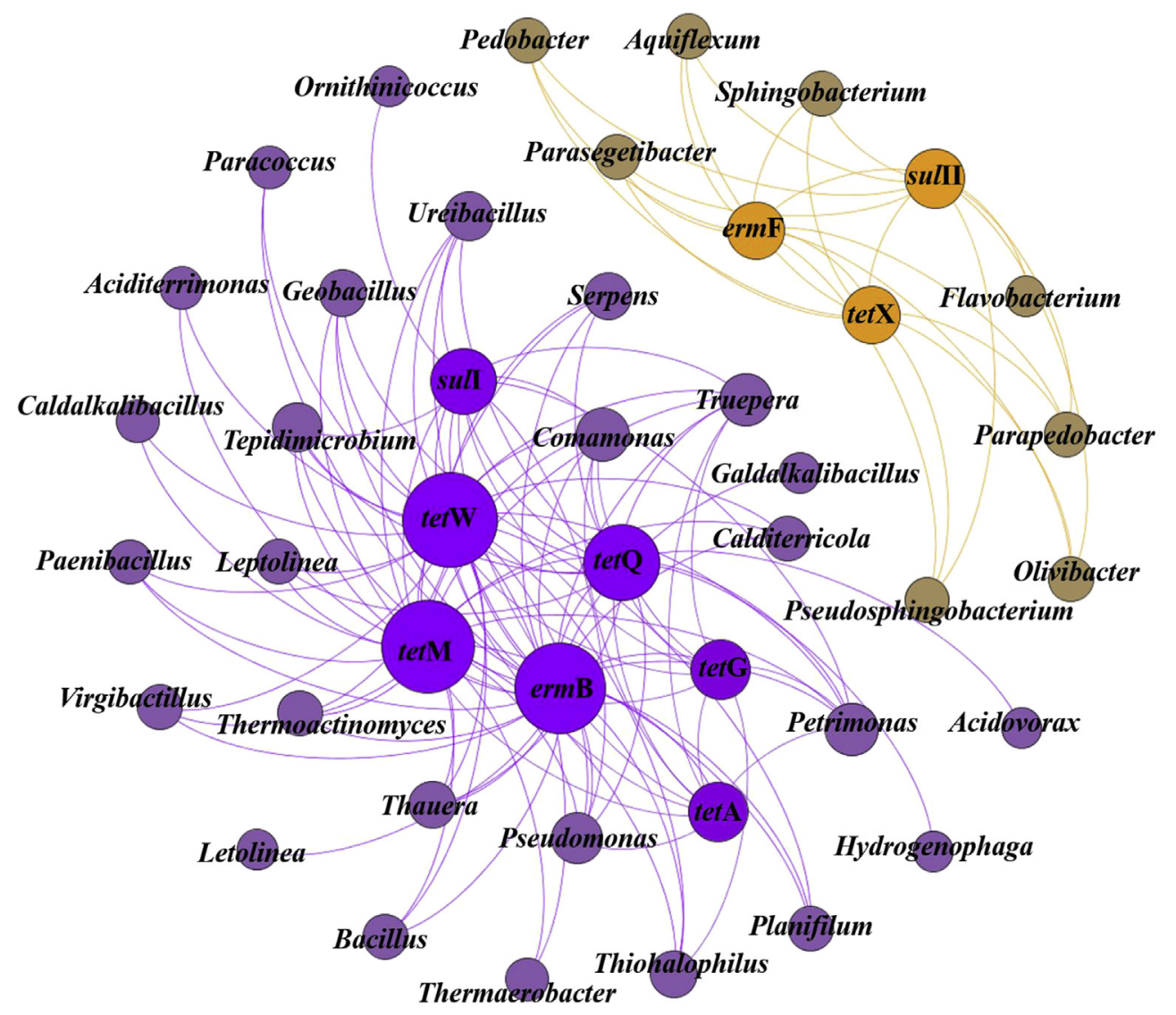

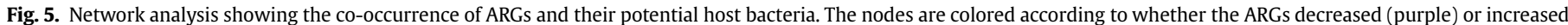

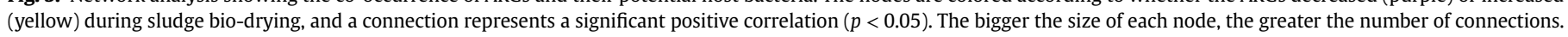

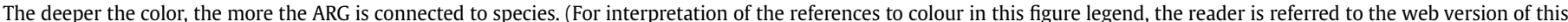
article.)

co-selection from heavy metals. The dominant contribution of bacterial community to the ARGs profile has been proved in various environments (Czekalski et al., 2014; Forsberg et al., 2014; Stepanauskas et al., 2005; Udikovic-Kolic et al., 2014), while this was further elucidated in sludge bio-drying.

However, the less contribution of HGT through MGEs should not be overlooked, it should be emphasized instead, because the spread of ARGs through HGT had much higher risks than evolution of bacterial community (Martínez et al., 2015). The less contribution of MGEs might just indicate that the HGT through MGEs was not enough to obscure the significant correlation between evolution of ARGs and changes of bacterial community composition during sludge bio-drying. A previous study on sludge composting indicated that MGEs dominated the evolution of ARGs at the 
thermophilic stage when nutrition was released and microbial activity increased to the maximum, and these availed the HGT (Zhang et al., 2016a). There was also an obviously thermophilic stage during sludge bio-drying, and thus the HGT through MGEs should be paid attention concerning the reduction of the higher risks for the spread of ARGs at the thermophilic stage for sludge bio-drying.

Besides we should notice that although changes of bacterial community contributed the most to the ARGs profiles, it was not the decisive driver of the evolution of ARGs, i.e. changes of bacterial community composition was influenced significantly by environmental factors like $\mathrm{pH}$, the properties of available nutrition, temperature and MC, these factors may affect the ARGs profiles through bacterial community indirectly. The operational condition may be the primary factor that governs the evolution of bacterial community and the subsequent prevalence of ARGs as suggested previously in anaerobic digestion (Youngquist et al., 2016). Considering controlling the ARGs, more researches should be done to improve these environmental factors through optimization of the key operational parameters, just like what has been done in this study that the improved aeration strategy in Pile I realized the higher reduction and less enrichment of ARGs.

\section{Conclusions}

The potential of sludge bio-drying for ARGs control by the improved aeration strategy was investigated in this study. Conclusions and proposals are as follows:

- Sludge bio-drying could reduce most of ARGs, and showed some advantages on the ARGs reduction compared with other sludge treatment technologies.

- Concerning the enrichment of ermF, sulII and tetX in sludge bio-drying, this could be explained well by the evolution of BioCu and their potential host bacteria mainly existed in Bacteroidetes, not HGT through MGEs.

- The improved aeration strategy could both enhance the sludge bio-drying effects and ARGs reduction. Changes of bacterial community composition contributed most to the evolution of ARGs rather than HGT through MGEs or coselection from heavy metals.

- However, HGT through MGEs should be paid more attention due to its much higher risks compared with the evolution of bacterial community, especially at the thermophilic stage for sludge bio-drying.

\section{Conflict of interest}

The authors declare no conflict of interest.

\section{Acknowledgements}

This work is supported by the National Major Science \& Technology Projects for Water Pollution Control and Management of China (2012ZX07202-005) and the National Natural Science Foundation of China (21377151).

\section{Appendix A. Supplementary data}

Supplementary data related to this article can be found at http:// dx.doi.org/10.1016/j.watres.2016.09.055.

\section{References}

Amachawadi, R.G., Scott, H.M., Alvarado, C.A., Mainini, T.R., Vinasco, J.,
Drouillard, J.S., Nagaraja, T.G., 2013. Occurrence of the transferable copper resistance gene tcrB among fecal enterococci of U.S. feedlot cattle fed coppersupplemented diets. Appl. Environ. Microbiol. 79, 4369-4375.

Amachawadi, R.G., Scott, H.M., Vinasco, J., Tokach, M.D., Dritz, S.S., Nelssen, J.L., Nagaraja1, T.G., 2015. Effects of in-feed copper, chlortetracycline, and tylosin on the prevalence of transferable copper resistance gene, $\operatorname{tcr} B$, among fecal Enterococci of Weaned piglets. Foodborne Pathog. Dis. 12, 670-678.

Baker-Austin, C., Wright, M.S., Stepanauskas, R., McArthur, J.V., 2006. Co-selection of antibiotic and metal resistance. Trends Microbiol. 14, 176-182.

Bastian, M., Heymann, S., Jacomy, M., 2009. Gephi: an open source software for exploring and manipulating networks. BT - international AAAI Conference on Weblogs and Social. Proc. Third Int. ICWSM Conf. 8, 361-362.

Besaury, L., Bodilis, J., Delgas, F., Andrade, S., Iglesia, R.D.L., Ouddane, B., Quillet, L., 2013. Abundance and diversity of copper resistance genes cusA and copA in microbial communities in relation to the impact of copper on Chilean marine sediments. Mar. Pollut. Bull. 67 (1-2), 16-25.

Burch, T.R., Sadowsky, M.J., Lapara, T.M., 2014. Fate of antibiotic resistance genes and class 1 integrons in soil microcosms following the application of treated residual municipal wastewater solids. Environ. Sci. Technol. 48, 5620-5627.

Burch, T.R., Sadowsky, M.J., LaPara, T.M., 2013a. Air-drying beds reduce the quantities of antibiotic resistance genes and class 1 integrons in residual municipal wastewater solids. Environ. Sci. Technol. 47, 9965-9971.

Burch, T.R., Sadowsky, M.J., Lapara, T.M., 2013b. Aerobic digestion reduces the quantity of antibiotic resistance genes in residual municipal wastewater solids. Front. Microbiol. 4, 1-9.

Cheng, W., Chen, H., Su, C., Yan, S., 2013. Abundance and persistence of antibiotic resistance genes in livestock farms: a comprehensive investigation in eastern China. Environ. Int. 61, 1-7.

Clewell, D.B., Flannagan, S.E., Jaworski, D.D., 1995. Unconstrained bacterial promiscuity: the Tn916-Tn1545 family of conjugative transposons. Trends Microbiol. 3, 229-236.

Czekalski, N., Gascón Díez, E., Bürgmann, H., 2014. Wastewater as a point source of antibiotic-resistance genes in the sediment of a freshwater lake. ISME J. 8, 1381-1390.

Dar, O.A., Hasan, R., Schlundt, J., Harbarth, S., Caleo, G., Dar, F.K., Littmann, J., Rweyemamu, M., 2016. Exploring the evidence base for national and regional policy interventions to combat resistance. Lancet 387, 285-295.

Devi, P., Saroha, A.K., 2014. Risk analysis of pyrolyzed biochar made from paper mill effluent treatment plant sludge for bioavailability and eco-toxicity of heavy metals. Bioresour. Technol. 162, 308-315.

Diehl, D.L., Lapara, T.M., 2010. Effect of temperature on the fate of genes encoding tetracycline resistance and the integrase of class 1 integrons within anaerobic and aerobic digesters treating municipal wastewater solids. Environ. Sci. Technol. 44, 9128-9133.

Diop, C., Dewaelé, D., Cazier, F., Diouf, A., Ouddane, B., 2015. Assessment of trace metals contamination level, bioavailability and toxicity in sediments from Dakar coast and Saint Louis estuary in Senegal, West Africa. Chemosphere 138, 980-987.

Engemann, C.A., Keen, P.L., Knapp, C.W., Hall, K.J., Graham, D.W., 2008. Fate of tetracycline resistance genes in aquatic systems: migration from the water column to peripheral biofilms. Environ. Sci. Technol. 42, 5131-5136.

Forsberg, K.J., Patel, S., Gibson, M.K., Lauber, C.L., Knight, R., Fierer, N., Dantas, G., 2014. Bacterial phylogeny structures soil resistomes across habitats. Nature 509, 612-616.

Ghosh, S., Ramsden, S.J., LaPara, T.M., 2009. The role of anaerobic digestion in controlling the release of tetracycline resistance genes and class 1 integrons from municipal wastewater treatment plants. Appl. Microbiol. Biotechnol. 84, $791-796$.

Guo, G., Chen, T., Yang, J., Zheng, G., Gao, D., 2014. Regional distribution characteristics and variation of heavy metals in sewage sludge of China. Acta Sci. Circumstantiae 34, 2455-2461 (Chinese).

Ji, X., Shen, Q., Liu, F., Ma, J., Xu, G., Wang, Y., Wu, M., 2012. Antibiotic resistance gene abundances associated with antibiotics and heavy metals in animal manures and agricultural soils adjacent to feedlots in Shanghai. China. J. Hazard. Mater. 235, 178-185.

Jin, L., Zhang, G., Tian, H., 2014. Current state of sewage treatment in China. Water Res. 66, 85-98.

Li, L., Xu, Z., Wu, J., Tian, G., 2010. Bioaccumulation of heavy metals in the earthworm Eisenia fetida in relation to bioavailable metal concentrations in pig manure. Bioresour. Technol. 101, 3430-3436.

Ma, Y., Wilson, C.A., Novak, J.T., Riffat, R., Aynur, S., Murthy, S., Pruden, A., 2011. Effect of various sludge digestion conditions on sulfonamide, macrolide, and tetracycline resistance genes and class I integrons. Environ. Sci. Technol. 45, 7855-7861.

Martínez, J.L., Coque, T.M., Baquero, F., 2015. What is a resistance gene? Ranking risk in resistomes. Nat. Rev. Microbiol. 13, 116-123.

Mazel, D., 2006. Integrons: agents of bacterial evolution. Nat. Rev. Microbiol. 4, 608-620.

McArthur, A.G., Waglechner, N., Nizam, F., Yan, A., Azad, M.A., Baylay, A.J., Bhullar, K., Canova, M.J., De Pascale, G., Ejim, L., Kalan, L., King, A.M., Koteva, K., Morar, M., Mulvey, M.R., O'Brien, J.S., Pawlowski, A.C., Piddock, L.J.V., Spanogiannopoulos, P., Sutherland, A.D., Tang, I., Taylor, P.L., Thaker, M., Wang, W., Yan, M., Yu, T., Wright, G.D., 2013. The comprehensive antibiotic resistance database. Antimicrob. Agents Chemother. 57, 3348-3357.

Munir, M., Wong, K., Xagoraraki, I., 2011. Release of antibiotic resistant bacteria and 
genes in the effluent and biosolids of five wastewater utilities in Michigan. Water Res. 45, 681-693.

Navaee-Ardeh, S., Bertrand, F., Stuart, P.R., 2010. Key variables analysis of a novel continuous biodrying process for drying mixed sludge. Bioresour. Technol. 101, 3379-3387.

Roberts, M.C., 2005. Update on acquired tetracycline resistance genes. FEMS Microbiol. Lett. 245, 195-203.

Roosa, S., Wattiez, R., Prygiel, E., Lesven, L., Billon, G., Gillan, D.C., 2014. Bacterial metal resistance genes and metal bioavailability in contaminated sediments. Environ. Pollut. 189, 143-151.

Seiler, C., Berendonk, T.U., 2012. Heavy metal driven co-selection of antibiotic resistance in soil and water bodies impacted by agriculture and aquaculture. Front Microbiol. 3, 1-10.

Stepanauskas, R., Glenn, T.C., Jagoe, C.H., Tuckfield, R.C., Lindell, A.H., McArthur, J.V., 2005. Elevated microbial tolerance to metals and antibiotics in metalcontaminated industrial environments. Environ. Sci. Technol. 39, 3671-3678.

Su, J., Ouyang, W., Wei, B., Huang, F., Zhao, Y., Xu, H., Zhu, Y.-G., 2015. Antibiotic resistome and its association with bacterial communities during sewage sludge composting. Environ. Sci. Technol. 49, 7356-7363.

Tessier, a., Campbell, P.G.C., Bisson, M., 1979. Sequential extraction procedure for the speciation of particulate trace metals. Anal. Chem. 51, 844-851.

Toleman, M.A., Bennett, P.M., Walsh, T.R., 2006. ISCR elements: novel genecapturing systems of the 21st century? Microbiol. Mol. Biol. Rev, 70, 296-316.

Udikovic-Kolic, N., Wichmann, F., Broderick, N.A., Handelsman, J., 2014. Bloom of resident antibiotic-resistant bacteria in soil following manure fertilization. Proc. Natl. Acad. Sci.U. S. A. 111, 15202-15207.

USEPA, 2007. Microwave Assisted Acid Digestion of Sediments,Sludge,Soils, and Oils.

Versporten, A., Bolokhovets, G., Ghazaryan, L., Abilova, V., Pyshnik, G., Spasojevic, T., Korinteli, I., Raka, L., Kambaralieva, B., Cizmovic, L., Carp, A., Radonjic, V., Maqsudova, N., Celik, H.D., Payerl-Pal, M., Pedersen, H.B., Sautenkova, N. Goossens, H., 2014. Antibiotic use in eastern Europe: a cross-national database study in coordination with the WHO Regional Office for Europe. Lancet Infect. Dis. 3099, 1-7.

Wang, F., Qiao, M., Su, J., Chen, Z., Zhou, X., Zhu, Y., 2014a. High throughput profiling of antibiotic resistance genes in Urban Park soils with reclaimed water irrigation. Environ. Sci. Technol. 48, 9079-9085.

Wang, F., Wang, H., Al-Tabbaa, A., 2014b. Leachability and heavy metal speciation of 17-year old stabilised/solidified contaminated site soils. J. Hazard. Mater. 278, $144-151$.

Wei, Y., Van Houten, R.T., Borger, A.R., Eikelboom, D.H., Fan, Y., 2003. Minimization of excess sludge production for biological wastewater treatment. Water Res. 37, 4453-4467.

Winkler, M.K.H., Bennenbroek, M.H., Horstink, F.H., van Loosdrecht, M.C.M., van de Pol, G.J., 2013. The biodrying concept: an innovative technology creating energy from sewage sludge. Bioresour. Technol. 147, 124-129.

Xiong, W., Zeng, Z., Zhang, Y., Ding, X., Sun, Y., 2015. Fate of metal resistance genes in arable soil after manure application in a microcosm study. Ecotoxicol. Environ. Saf. 113, 59-63.

Yang, Y., Li, B., Zou, S., Fang, H.H.P.P., Zhang, T., 2014. Fate of antibiotic resistance genes in sewage treatment plant revealed by metagenomic approach. Water Res. 62, 97-106.

Youngquist, C.P., Mitchell, S.M., Cogger, C.G., 2016. Fate of antibiotics and antibiotic resistance during digestion and composting: a review. J. Environ. Qual. 45, 537. http://dx.doi.org/10.2134/jeq2015.05.0256.

Zhang, J., Cai, X., Qi, L., Shao, C., Lin, Y., Zhang, J., Zhang, Y., Shen, P., Wei, Y., 2015 Effects of aeration strategy on the evolution of dissolved organic matter (DOM) and microbial community structure during sludge bio-drying. Appl. Microbiol. Biotechnol. 99, 7321-7331.

Zhang, J., Chen, M., Sui, Q., Tong, J., Jiang, C., Lu, X., Zhang, Y., Wei, Y., 2016a. Impacts of addition of natural zeolite or a nitrification inhibitor on antibiotic resistance genes during sludge composting. Water Res. 91, 339-349.

Zhang, J., Chen, M., Sui, Q., Wang, R., Tong, J., Wei, Y., 2016b. Fate of antibiotic resistance genes and its drivers during anaerobic co-digestion of food waste and sewage sludge based on microwave pretreatment. Bioresour. Technol. http://dx.doi.org/10.1016/j.biortech.2016.02.140.

Zhao, L., Gu, W.-M., He, P.-J., Shao, L.-M., 2010. Effect of air-flow rate and turning frequency on bio-drying of dewatered sludge. Water Res. 44, 6144-6152.

Zhao, L., Gu, W.-M., He, P.-J., Shao, L.-M., 2011. Biodegradation potential of bulking agents used in sludge bio-drying and their contribution to bio-generated heat. Water Res. 45, 2322-2330. http://dx.doi.org/10.1016/j.watres.2011.01.014. 